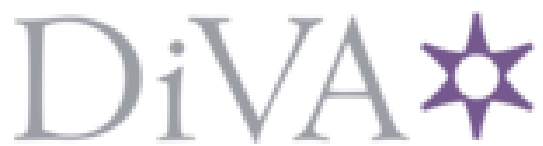

http://www.diva-portal.org

This is the published version of a paper published in Wood and Fiber Science.

Citation for the original published paper (version of record):

Florisson, S., Ormarsson, S., Vessby, J. (2019)

A numerical study of the effect of green-state moisture content on stress development in timber boards during drying

Wood and Fiber Science, 51(1): 41-57

https://doi.org/10.22382/wfs-2019-005

Access to the published version may require subscription.

N.B. When citing this work, cite the original published paper.

Permanent link to this version:

http://urn.kb.se/resolve?urn=urn:nbn:se:kau:diva-74373 


\title{
A NUMERICAL STUDY OF THE EFFECT OF GREEN-STATE MOISTURE CONTENT ON STRESS DEVELOPMENT IN TIMBER BOARDS DURING DRYING
}

\author{
S. Florisson*† \\ $\mathrm{PhD}$ Student \\ E-mail: sara.florisson@lnu.se \\ S. Ormarsson† \\ Professor \\ E-mail: sigurdur.ormarsson@lnu.se \\ J. Vessby† \\ Senior lecturer \\ E-mail: johan.vessby@lnu.se
}

(Received February 2018)

\begin{abstract}
Timber boards manufactured with a traditional sawing pattern often contain both heartwood and sapwood. In such boards, internal constraints can occur during drying because of a radial variation in greenstate (GS) MC between the heartwood (30-60\%) and sapwood region (120-200\%). Despite such knowledge, the initial MC is seldom considered when evaluating kiln-drying schedules. The effect of GS MC on the development of tangential tensile stress during drying is studied for four types of timber boards. A numerical model was developed that can simulate transient nonlinear orthotropic moisture flow and moisture-induced stress and distortion in wood with the use of the finite element method. The stress analysis considers elastic, hygroscopic, and mechano-sorptive strain. The study shows that the GS MC does not significantly influence the maximum stress state, but that it does influence the time at which the maximum tangential tensile stress occurs at different exchange surfaces. This results in several periods in the drying schedule where unfavorable high stress situations in the tangential direction arise, which could lead to crack propagation.
\end{abstract}

Keywords: Green state, nonlinear, numerical, moisture transport, transient, timber drying, tangential stress.

\section{INTRODUCTION}

A variation in initial MC exists in timber boards fabricated from Norway spruce with a plain, rift, or quarter sawn. This variation occurs because such boards often contain both heartwood and sapwood in their cross-section. This article will focus on the effect of such green-state (GS) MC on the time, location, and size of critical tangential tensile stress values when they are dried from GS to EMC. These aspects are important to consider when the quality of timber boards needs to be managed against possible cracking and distortion during kiln-drying.

\footnotetext{
* Corresponding author

$\dagger$ SWST member
}

\section{Physical Phenomenon of Moisture Transport in Wood}

GS MC. The MC when felling a tree is referred to as the GS MC (Skaar 1988). For softwood species, such as Norway spruce (Picea abies) and Scots pine (Pinus sylvestris), this state of MC equilibrium is characterized by a radial variation that can range from $30 \%$ to $60 \%$ in the heartwood region and 120-200\% in the sapwood region (Salin 1992; Samuelsson and Arfvidsson 1994; Absetz 1999; Larsen and Ormarsson 2012b; Larsen 2013). The variation is most clear and abrupt at the intersection of heartwood and sapwood, as seen in Fig 1. The pits in green sapwood are unaspirated and allow for an undisturbed flow of liquid water between the tracheids (Pang et al 1995). The cells in heartwood 


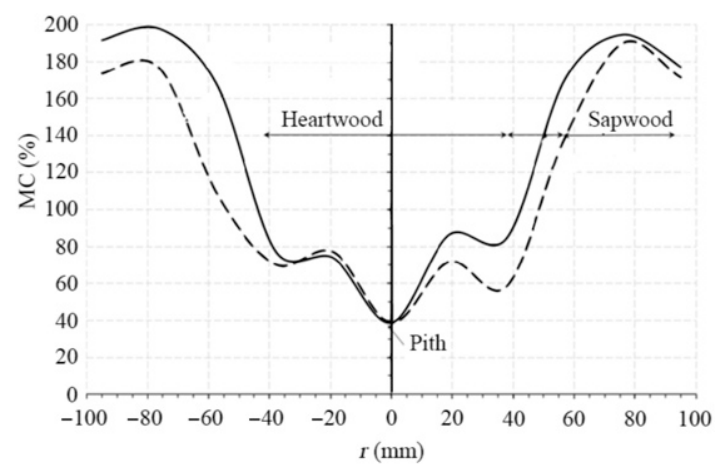

(a)

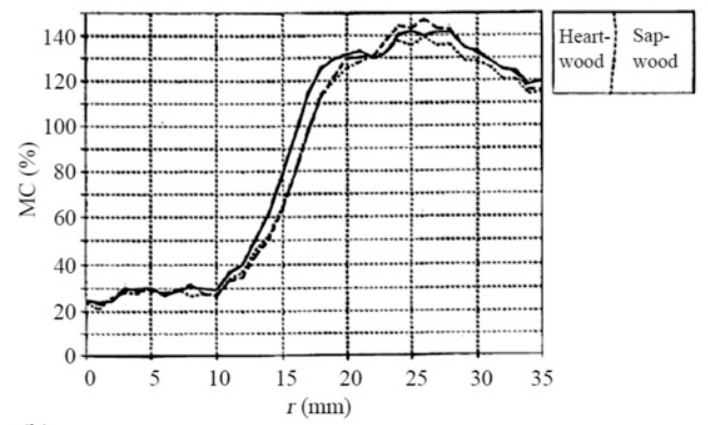

(b)

Figure 1. Green state moisture variation in the radial direction $r$ (a) obtained by slicing the cross-section and applying the oven-dry method (Larsen 2013, p. 41; Larsen and Ormarsson 2012b) and (b) obtained with X-ray attenuation (Absetz 1999, p. 12) for Norway spruce.

are dead, resulting in lower GS MC. The heartwood is also less permeable to moisture because of pit aspiration that occurs during the formation of heartwood and when felling the tree (Pang et al 1995).

Drying above fibre saturation point (FSP). The physical phenomena experienced during drying separate the wood-drying process into two significant phases; one above fibre saturation point (FSP) and one below FSP. Research shows that the physical behavior of moisture transport above FSP is still under great discussion. Most research articles indicate that the free water in sapwood migrates, because of capillary forces, toward an exchange surface or evaporation plane, where the bound-water diffusion controls the drying rate. Whether the position of the evaporation plane coincides with the exchange surface, ie the physical surface of wood is not always determined. Wiberg (1996) simply suggests, based on MC profiles obtained with computerized tomography (CT) scanning, that the free water in sapwood migrates because of capillary forces toward the exchange surface, which results in gradient-free drying up to where the cross-section reaches FSP, as in Fig 2 (Wiberg 1998).

Pang et al (1995) and Rémond et al (2005) introduce the concept of evaporation plane, which is not necessarily located at the exchange surface. This plane divides the wood material into a wet zone underneath the plane and a dry zone above the plane. They state that free water in the wet zone moves according to the principles of capillary force in the direction of the evaporation surface. In the dry zone, the bound water and water vapor flow is governed by diffusion. Pang

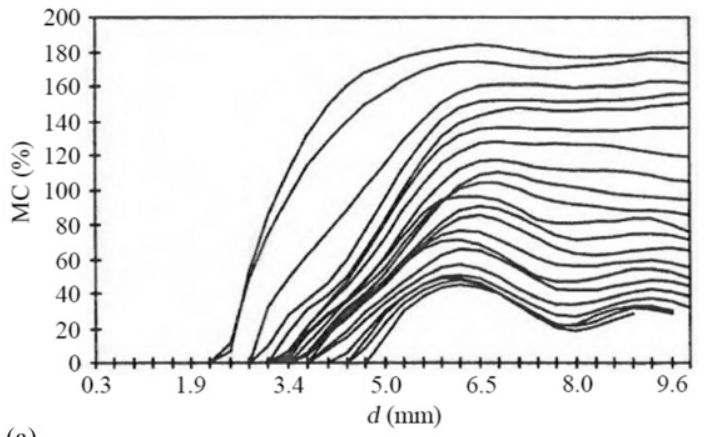

(a)

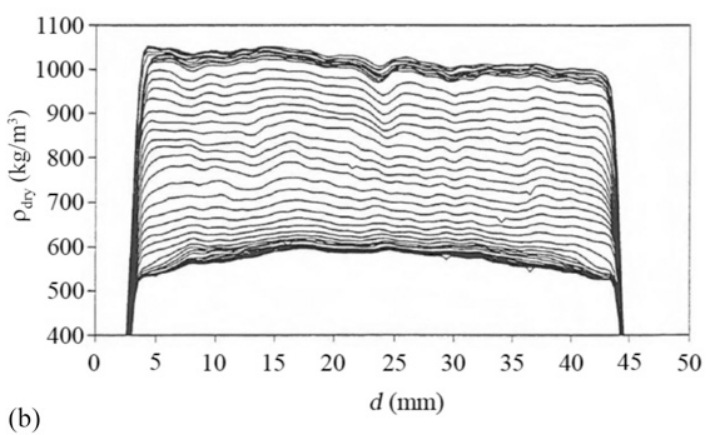

Figure 2. (a) MC profile from surface to center of sample and (b) density profile from surface to surface obtained with CT scanning and digital image processing for timber boards of Scots pine (Wiberg 1996, 1998). 
et al (1995) and Rémond et al (2005) suggest that the evaporation plane recedes into the material in the first phase of drying. Rémond et al (2005) propose a division of this first phase into two distinctive periods; a constant drying rate period and a pseudo-constant drying rate period.

At the beginning of the first period the evaporation surface moves slightly inward, creating a dry shell just below the exchange surface, as seen in Fig 2 (Pang et al 1995; Wiberg 1998). A balance between heat and mass transfer exists at the boundary and the drying rate is constant (Rémond et al 2005). The end of the constant drying period is indicated by the point of irreducible saturation (Eriksson 2005; Eriksson et al 2007). Some researchers believe that below this point, the flow governed by capillary pressure is no longer possible because of the interruption of the liquid path (Spolek and Plumb 1981; Nijdam et al 2000; Rosenkilde 2002). Krabbenhøft (2003), however, mentions that at lower degrees of saturation, free water collects at the ends of the tapered tracheids, and transport mainly takes place through the bordered pits. Salin $(2008,2010)$ suggests that a continuation of the liquid phase is established through possible links between water-filled clusters in the form of films, as seen with other materials.

The pseudo-constant drying rate period is characterized by a reduction in the drying rate, an increase in temperature, and a sensitivity to surface cracking. Pang et al (1995) and Rémond et al (2005) explain these phenomena as an inwardly receding evaporation front. This recession leads to an increasing length, that the water vapor needs to bridge to reach the exchange surface. Nonetheless, Wiberg (1996, 1998) presented experimental data in Fig 2 that does not indicate such further penetration of the evaporation surface. Rémond et al (2005) present experimental data that do show a drop in the drying rate during this second period. Finally, heartwood experiences similar phenomena. However, the drying process is only initiated in the pseudo-constant drying rate period because of the lower initial MC state and not in the constant drying rate period as seen with sapwood (Pang et al 1995; Rémond et al 2005).

Dry shell. The aforementioned dry shell is signified by a rapidly receding evaporation surface, just below the material surface, at the beginning of the constant drying-rate period. This receding surface results in a steep gradient at the material surface and a high neighboring uniform MC level, Fig 2 (Pang et al 1995; Wiberg 1996; Wiberg and Morén 1999; Rosenkilde 2002; Salin 2010). The dry shell can develop because of damaged surface cells and aspiration of pits because of the processing of wood. The steepness of the gradient is dependent on the roughness of the surface layer (Eriksson 2005; Salin 2008). Wiberg and Morén (1999), and Pang et al (1995) suggest a gradient between 0.2 and $1.0 \mathrm{~mm}$. This value should provide a distinction between the dry shell and the previously discussed receding evaporation front that was suggested by Pang et al (1995) and Rémond et al (2005) during the pseudo-constant drying rate period. Rémond et al (2005) question the existence of the thin dry shell, and, thus, call the recession of the evaporation plane during the pseudo-constant drying rate period the thin dry layer.

Drying below FSP. The second drying phase starts after the MC level reaches FSP, ie the decreasing drying rate period or the hygroscopic range (Pang et al 1995; Rémond et al 2005).The FSP indicates whether the cell walls are completely saturated with water, and no capillary water exists in the lumen or voids (Siau 1995; Dinwoodie 2000). According to Eitelberger and Hofstetter (2011), such a situation agrees with a $\mathrm{RH}$ of about $98 \%$. In the hygroscopic range, the drying process is controlled by bound-water diffusion in the cell walls and the water vapor flow in the lumen. Hygroscopic strain occurs in this range, and the mechanical material properties are influenced by MC, eg see Ormarsson et al (1998).

Surface emission and diffusion. The previously mentioned dry shell contributes to the external resistance against moisture transport and 
translates into an external mass transfer coefficient, or the more commonly used surface emission coefficient (SEC). The coefficient is a function of fluid characteristics such as temperature, velocity, and viscosity, and wood characteristics such as specific gravity, MC, and surface conditions (Siau and Avramidis 1996; Perré 2007). Similarly, the internal resistance against moisture transport is expressed by the diffusion coefficient (DC), which is a function of properties such as the composition of wood, temperature, and MC.

A correct mutual correlation between DC and SEC is vital to drying speed and the formation of moisture gradients close to the exchange surface. A relatively high SEC with regard to DC leads to receding steep gradients, whereas a relatively low SEC in terms of DC leads to flat MC profiles. Both coefficients are MC dependent. Siau (1995) shows how the value of DC exponentially decays with decreasing $\mathrm{MC}$, whereas Yeo and Smith (2005) show the opposite effect for SEC. This difference contributes to the observation made by Wiberg (1998), where the dry shell starts to move inward only when the MC reaches FSP, indicating a lower resistance at the exchange surface and a higher SEC value; see Fig 2.

\section{Modeling of Moisture Transport in Wood}

Current state of knowledge. Total moisture diffusion models and phase separation models are used to model the moisture transport above and below FSP. The total moisture diffusion models, ie the Fickian models, describe the flux to be driven by a moisture gradient, and should be proportional to the DC. Fick's first law is a constitutive law and describes the moisture flux, whereas Fick's second law is a differential equation and is applicable when the MC is changing in time (Fick 1995). Fick's laws assume internal moisture equilibrium to be a function of $\mathrm{RH}$ given by the sorption isotherm (Krabbenhøft 2003). Applying these laws seems to give acceptable results below FSP, when relative slow transfer under isothermal conditions is assumed, and only one material property to simulate the physical behavior of flow is required, viz the DC. The application seems less fruitful when only a small internal resistance to water vapor diffusion is encountered compared with the rate of sorption into the cell wall (Krabbenhøft 2003). This phenomenon might be because vapor penetrates the wood rapidly along available paths and voids, but absorbs moisture into the cell wall rather slowly (Salin 2010).

A more advanced way to model mass transport is via the phase separation model, also mentioned as the dual diffusion model or model for multiFickian behavior (Pang et al 1995; Perré and Turner 1999; Krabbenhøft 2003; Salin 2010; Eitelberger and Hofstetter 2011; Eitelberger et al 2011; Fortino et al 2013). Phase separation models treat the transport of free water, bound water, water vapor, and dry air with separate conservation equations, and use coupling terms to create links between the different phases (Krabbenhøft 2003; Salin 2010). For high-temperature drying, the conservation of mass needs to be complemented with the conservation of enthalpy or energy, which considers the conduction of heat, the changes in enthalpy due to phase change, and the convection of heat transfer (Krabbenhøft 2003; Fortino et al 2013). In Rémond et al (2005), such models are still incapable of describing all physical phenomena, especially for transport above FSP. Such phenomena can be referred to as non-Fickian effects.

The phase separation model is used in combination with Darcy's law for capillary flow and a separate Fick's law for bound-water diffusion and water vapor transport. The flow of liquid water through wood can be described as a gradientdriven phenomenon, when the capillary pressure can be established. Spolek and Plumb (1981) accomplish this by associating the capillary pressure with the level of saturation. Nevertheless, the use of Darcy's equation (Darcy 1856) seems to deviate from experimental results when applied for heartwood or kiln-dried interior sapwood, whereas it does not consider random blockage of tracheids due to aspirated pits (Bramhall 1971). In addition, this equation does not seem to account for physical phenomena, such as dry shell, gradient-free drying, and length 
scale effect. To enclose these phenomena, Salin (2006a, 2006b, 2008, 2010) proposes the application of percolation theory, where a stochastic process describes the transport of moisture between tracheids.

Moisture and stress model. In this article, a three-dimensional numerical model will be presented, which is able to simulate moisture flow and moisture-induced stress development in timber boards. The model operates on a continuum level and consists of a total diffusion model, ie a transient nonlinear orthotropic Fickian model, and a moisture-induced stress model, ie distortion model, that regard elastic, hygroscopic, and mechano-sorptive strain behavior with the use of the finite element method. Ormarsson (1999) and Ormarsson et al (1998, 1999a, 1999b) previously developed the distortion model, which was extended in this article by adding a transient nonlinear moisture flow model that is able to simulate flow above and below FSP and regards an initial variation in MC and a boundary layer resistance, ie a convective boundary condition.

\section{BRIEF DESCRIPTION OF FE-FORMULATION}

\section{Transient Nonlinear Moisture Flow}

The nonlinear orthotropic moisture transport above and below FSP is modeled using Fick's first law of diffusion as introduced in the section Current state of knowledge. As discussed in this section, the application of this law is straightforward and effective when applied for low isothermal drying conditions and requires only one type of material property, specifically the DC for orthotropic material. Although this law does not represent the exact physical behavior above FSP, it can simulate gradient-free drying fairly well. In this chapter, a brief description of the three-dimensional finite element $(\mathrm{FE})$ formulation of nonlinear transient flow is given.

Constitutive equation. Fick's first law, Eq 1, describes the moisture flux $\overline{\mathbf{q}}$ to be proportional to the moisture-dependent diffusion matrix $\overline{\mathbf{D}}(w)$ governed by the moisture gradient vector $\bar{\nabla} w$. The bar indicates that the orthotropic material directions refer to the orientation of the orthogonal local coordinate system. The same formulation in rate form is presented in Eq 2, where the dot indicates a change with respect to time.

$$
\begin{gathered}
\overline{\mathbf{q}}=-\overline{\mathbf{D}} \bar{\nabla} w \\
\dot{\overline{\mathbf{q}}}=-\dot{\overline{\mathbf{D}}} \bar{\nabla} w-\overline{\mathbf{D}} \bar{\nabla} \dot{w}
\end{gathered}
$$

The moisture flux $\overline{\mathbf{q}}$, diffusion matrix $\overline{\mathbf{D}}(w)$, and moisture-gradient vector $\bar{\nabla} w$ can be transformed between the local and global coordinate systems by means of the transformation matrix $\mathbf{A}$; see Eqs 3-5. This matrix can account for pith direction and annual ring orientation $\mathbf{A}_{0}$, conical shape $\mathbf{A}_{\mathrm{c}}$, and spiral grain $\mathbf{A}_{\mathrm{s}}$, and is presented in $\mathrm{Eq} 6$. The origins of these matrices are found in Ormarsson (1999) and Ormarsson et al (1998).

$$
\begin{aligned}
& \mathbf{q}=\mathbf{A} \overline{\mathbf{q}} \\
& \nabla w=\mathbf{A} \bar{\nabla} w \\
& \mathbf{D}=\mathbf{A} \overline{\mathbf{D}} \mathbf{A}^{T} \\
& \mathbf{A}=\mathbf{A}_{0} \mathbf{A}_{\mathrm{c}} \mathbf{A}_{\mathrm{s}}=\left[\begin{array}{ccc}
l_{0 x} & r_{0 x} & t_{0 x} \\
l_{0 y} & r_{0 y} & t_{0 y} \\
l_{0 z} & r_{0 z} & t_{0 z}
\end{array}\right] \\
& {\left[\begin{array}{ccc}
\cos \phi & -\sin \phi & 0 \\
\sin \phi & \cos \phi & 0 \\
0 & 0 & 1
\end{array}\right]} \\
& {\left[\begin{array}{ccc}
\cos \theta & 0 & \sin \theta \\
0 & 1 & 0 \\
-\sin \theta & 0 & \cos \theta
\end{array}\right]}
\end{aligned}
$$

Strong formulation. The strong formulation of the transient nonlinear flow is given in Eq 7. The formulation is known as Fick's second law of diffusion as presented in the section Current state of knowledge, and is nonlinear because of moisture dependency of the diffusion matrix $\overline{\mathbf{D}}(w)$. Eq 8 presents the convective boundary condition, Eq 9 the natural boundary condition, and Eq 10 the essential boundary condition, 


$$
\begin{aligned}
\frac{\partial w}{\partial t} & =\operatorname{div}(\mathbf{D}(w) \nabla w)+Q \text { in region } V \\
q_{n} & =s(w)\left(w-w_{\infty}\right) \text { on surface } S_{c} \\
q_{n} & =\mathbf{q}^{\mathrm{T}} \mathbf{n}=h \text { on surface } S_{h} \\
w & =g \text { on surface } S_{g}
\end{aligned}
$$

where $\partial w / \partial t$ is the rate of moisture change, $Q$ is the moisture supplied to the body per unit time, and $q_{n}$ is the flux normal to the exchange surface. The convective boundary condition described by Eq 8 is vital to this article. The condition describes the flux to be proportional to the MCdependent SEC $s(w)$ and the driver $\left(w-w_{\infty}\right)$ expressed as the difference between surface MC and the MC of the ambient air.

Finite element formulation. The nonlinear finite-element formulation is presented in Eq 11, and Eqs 12-16 present an elaboration of the different matrices. The used approximation $w(x, y, z, t)=\mathbf{N}(x, y, z) \mathbf{a}(t)$ for the MC shows the shape functions to be position dependent and the nodal point values to be time dependent. The derivation of $w(x, y, z, t)$ with respect to time gives $d w / d t=\mathbf{N a}$, where $\dot{\mathbf{a}}=d \mathbf{a} / d t$. The convective boundary condition results in a complementary matrix, but is also present in the boundary vector $\mathbf{f}_{b}$.

$$
\begin{aligned}
& \left(\mathbf{K}+\mathbf{K}_{c}\right) \mathbf{a}+\mathbf{C} \dot{\mathbf{a}}=\mathbf{f}_{b}+\mathbf{f}_{l} \\
& \mathbf{K}=\int_{V} \mathbf{B}^{T} \mathbf{D}(w) \mathbf{B} d V \\
& \mathbf{K}_{c}=\int_{S_{c}} s(w) \mathbf{N}^{\mathrm{T}} \mathbf{N} d S \\
& \mathbf{C}=\int_{V} \mathbf{N}^{\mathrm{T}} \mathbf{N} d V \\
& \mathbf{f}_{b}=-\int_{S_{h}} \mathbf{N}^{\mathrm{T}} h d S-\int_{S_{g}} \mathbf{N}^{\mathrm{T}} q_{n} d S+w_{\infty} \int_{S_{c}} \mathbf{N}^{\mathrm{T}} s(w) d S
\end{aligned}
$$

$$
\mathbf{f}_{l}=\int_{V} \mathbf{N}^{T} Q d V
$$

Ottosen and Petersson (1992) present a more detailed description of the finite-element formulation for convective boundary condition and Zienkiewicz and Taylor (1991) present nonlinear transient moisture flow.

\section{Moisture-Related Deformations and Stress}

The constitutive relation for the stress simulation is given as

$$
\dot{\overline{\boldsymbol{\sigma}}}=\overline{\mathbf{C}}^{-1}\left(\dot{\overline{\boldsymbol{\varepsilon}}}-\dot{\overline{\mathbf{C}}} \overline{\boldsymbol{\sigma}}-\dot{\overline{\boldsymbol{\varepsilon}}}_{h}-\dot{\overline{\boldsymbol{\varepsilon}}}_{w s}\right)
$$

where the total strain and the elastic strain are given by

$$
\begin{gathered}
\dot{\overline{\boldsymbol{\varepsilon}}}=\dot{\overline{\boldsymbol{\varepsilon}}}_{e}+\dot{\overline{\boldsymbol{\varepsilon}}}_{h}+\dot{\overline{\boldsymbol{\varepsilon}}}_{w s} \\
\dot{\overline{\boldsymbol{\varepsilon}}}_{e}=\overline{\mathbf{C}} \dot{\overline{\boldsymbol{\sigma}}}+\dot{\overline{\mathbf{C}}} \overline{\boldsymbol{\sigma}} .
\end{gathered}
$$

The constitutive relation consists of the elastic strain rate $\dot{\overline{\boldsymbol{\varepsilon}}}_{e}$, hygroscopic strain rate $\dot{\overline{\boldsymbol{\varepsilon}}}_{h}$, and mechano-sorptive strain rate $\dot{\overline{\boldsymbol{\varepsilon}}}_{w s}$. The elastic strain rate is expressed as the generalized Hooke's law using the local compliance matrix $\overline{\mathbf{C}}$ and its rate $\dot{\overline{\mathbf{C}}}$, and the local stress matrix $\overline{\boldsymbol{\sigma}}$ and its rate $\dot{\overline{\boldsymbol{\sigma}}}$. The matrix formulation for the different strain components and the finite element formulation are found in Ormarsson (1999) and Ormarsson et al (1998).

\section{NUMERICAL EXAMPLE}

\section{Problem Description}

Model description. A three-dimensional numerical model was created in the finite element software ABAQUS ${ }^{\odot}$ (Johnston, RI), patch number 2016. The simulation model consists of two types of analysis: a transient nonlinear moisture-flow analysis and the stress analysis that considers elastic, hygroscopic, and mechanosorptive strain. Output data from the moisture analysis function as input data for the stress analysis. A general purpose linear brick element 
Table 1. Impression of material properties and their relation to temperature and MC used in stress simulation.

\begin{tabular}{ll}
\hline$E_{r}=E_{r 0} \cdot\left(1+E_{r T}\left(T_{0}-T\right)\right)+E_{r w}\left(w_{f}-w_{a}\right)$ & Eq 20 \\
$G_{r t}=G_{r t 0} \cdot\left(1+G_{r t T}\left(T_{0}-T\right)\right)+G_{r t w}\left(w_{f}-w_{a}\right)$ & Eq 21 \\
$w_{f}=w_{f 0} \cdot\left(1+w_{f T}\left(T_{0}-T\right)\right)$ & Eq 22 \\
$m_{r}=m_{r 0} \cdot\left(1-m_{r T}\left(T_{0}-T\right)\right)$ & Eq 23 \\
\hline
\end{tabular}

is used for both moisture (DC3D8) and stress (C3D8) analyses. The element type combined with a characteristic edge length of $2 \mathrm{~mm}$ prevents spurious oscillation in the transient moisture analysis, which can be caused by steep gradients and perpendicular flow to the exchange surface. The model is scripted in Python ${ }^{(}$ (Wilmington, DE) to generate flexibility and the ability to perform parametric studies.

The three-dimensional formulation of the moisturedependent material behavior of wood was implemented in the user subroutine UMAT. All transformations of matrices between local and global coordinate systems for both moisture and

(a)

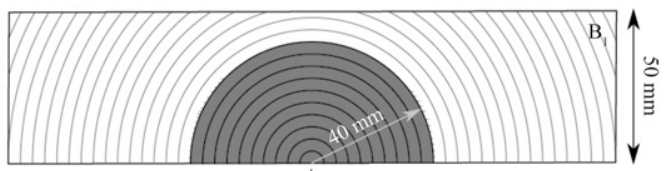

(b)

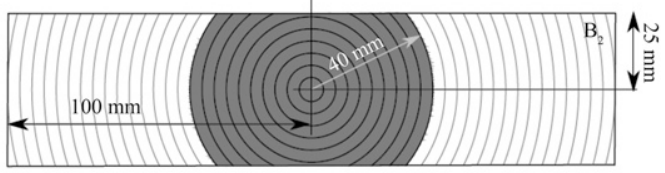

(c)
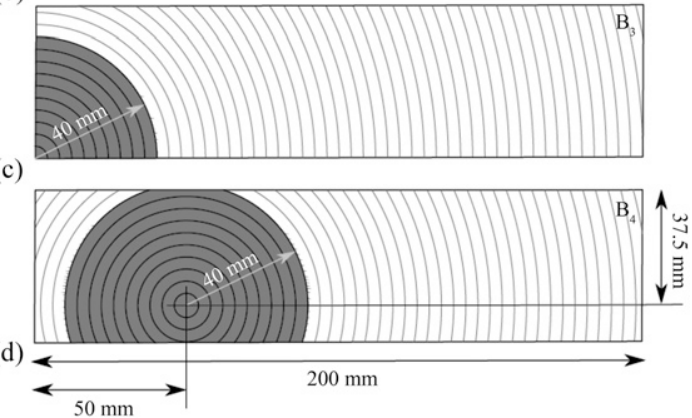

Figure 3. Four analyzed timber boards with a unique location of the pith with dimensions $50 \times 200 \mathrm{~mm}$ containing both heartwood (dark area) with radius of $40 \mathrm{~mm}$ and sapwood (light area): (a) timber board $\mathrm{B}_{1}$, (b) timber board $\mathrm{B}_{2}$, (c) timber board $\mathrm{B}_{3}$, and (d) timber board $\mathrm{B}_{4}$. stress simulations are implemented in the user subroutine ORIENT. The local coordinate system is used to define the orthotropic nature of wood and specify the longitudinal, radial, and tangential direction.

The material data needed to perform the nonlinear transient flow simulation can be found in section Green State MC and Surface Emission and Diffusion Coefficient. The material data needed to perform the stress analysis originates from Ormarsson et al (1998). A selection of parameters and their relation to temperature and $\mathrm{MC}$ can be found in Table 1. In this table, $E_{r}$ is the modulus of elasticity in the radial direction, $G_{r t}$ is the shear modulus in the radial-tangential plane, $w_{f}$ is the FSP, and $m_{r}$ is the mechano-sorption property in the radial direction. The parameters $E_{r 0}, G_{r t 0}, w_{f 0}, m_{r 0}$ are the basic values at the reference temperature of $T=T_{0}=20^{\circ} \mathrm{C}$. The parameters $E_{r T}, G_{r t T}, w_{f T}, m_{r T}$ describe the effect of temperature, and $E_{r w}, G_{r t w}$ describe the effect of MC. The shrinkage properties for heartwood $\left(\alpha_{r}=0.1\right.$ and $\left.\alpha_{t}=0.2\right)$ and sapwood $\left(\alpha_{r}=0.17\right.$ and $\left.\alpha_{t}=0.35\right)$ are taken from Larsen and Ormarsson (2012a) and Larsen (2013).

Study description. The simulation model in this article will be used to study the effect of initial MC variation on the development of tensile stress in the tangential direction $\sigma_{t}$. A tensile strength of $0.5 \mathrm{MPa}$ is assumed. This value corresponds to the weakest characteristic strength values of solid wood perpendicular to the grain. Figure 3 shows the four theoretical plain-sawn timber boards that were analyzed in this study. The boards have dimensions of $50 \times 200 \mathrm{~mm}$ and a unique pith location. The radius of the heartwood area was chosen according to the experimental data in Fig 1(a) and has a value of $40 \mathrm{~mm}$.

Two types of simulations were made for each timber board. The first simulation considered constant initial MC over the cross-section of $31 \%$. The second simulation took into account a variation in initial MC. This variation was created with the method presented in the following section. 


\section{Green State MC}

The initial moisture variation in the radial direction for the four timber boards is based on experimental data published by Larsen (2013). A polynomial expression was created by curvefitting the data using the least square method. The expression can be used in the simulation model to automatically generate an initial MC field based on the location of the pith, see Fig 4. The expression results in an MC variation, which runs from $28.4 \%$ in the pith location to a value between $105 \%$ and $190 \%$ at the exchange surfaces. The exact value is dependent on the distance between the pith and outermost surface.

\section{Surface Emission and Diffusion Coefficient}

In literature, it is difficult to find a coherent set of experimentally obtained moisture-dependent SEC and DC (Siau and Avramidis 1996) that can be used for the transient nonlinear moisture simulation. The experimentally obtained moisture profiles by Rosenkilde (2002) were used to obtain a sufficient set of moisture-dependent coefficients to simulate realistic MC profiles. This was carried out by adjusting the set of moisture-dependent SECs from Yeo and Smith (2005) and DCs from Siau and Avramidis (1996) until the simulations fitted the drying speed and

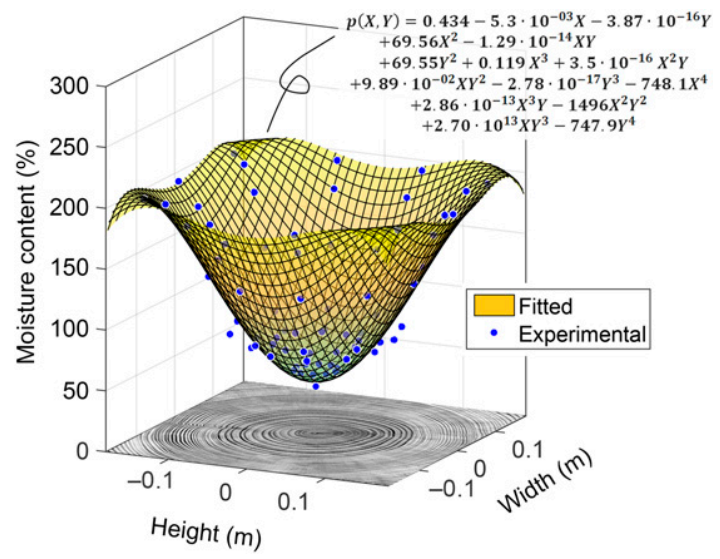

Figure 4. Green state MC data as presented in Figure 1 by Larsen (2013) and curve-fitted polynomial function used for the numerical simulations. curvature of the moisture profiles. The same climatic conditions apply for the experimental data and the simulation. The fitting is presented in Fig 5. The initial variation seen in Fig 5(a) was neglected because it is the result of premature drying and averaging of the MC of the wood slices.

The SEC data presented by Yeo and Smith (2005) and the data found with the fitting is presented in Fig 6. The values found with the fitting are much lower than the values found in literature. This implies a greater resistance at the boundary surface than for the experimentally obtained

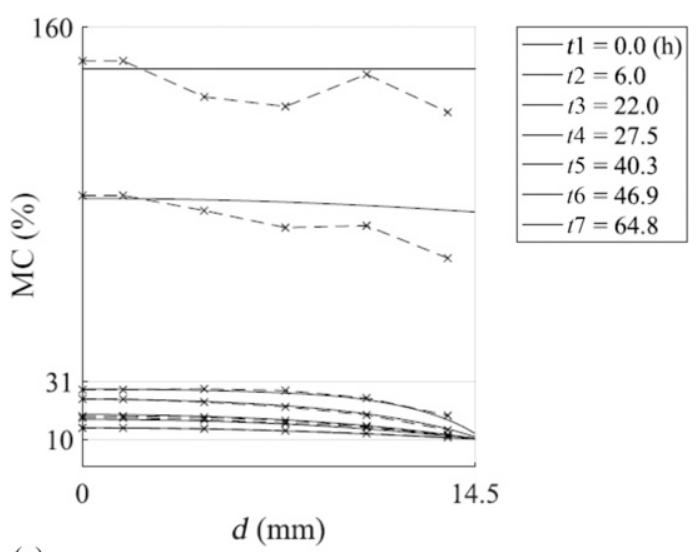

(a)

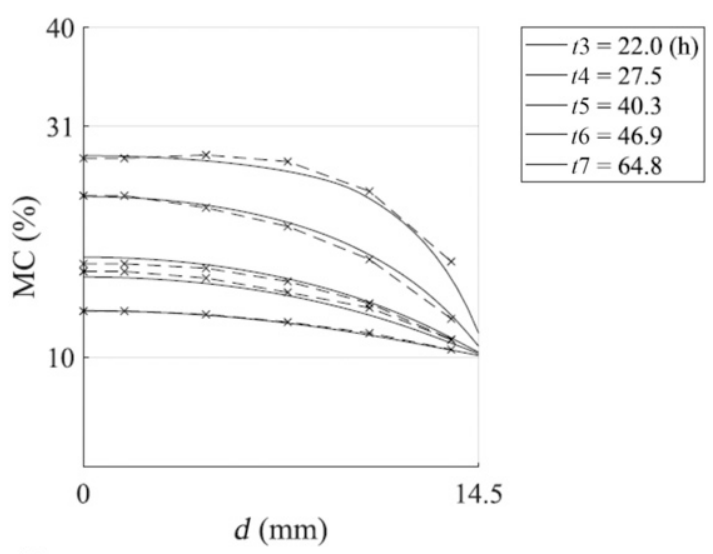

(b)

Figure 5. MC profiles obtained experimentally by Rosenkilde (2002) (dashed lines) and with nonlinear transient flow simulation model (solid lines) (a) MC profiles from center to surface, above and below FSP (b) MC profiles from center to surface, below FSP. The simulation was used to obtain SEC and DC data. 


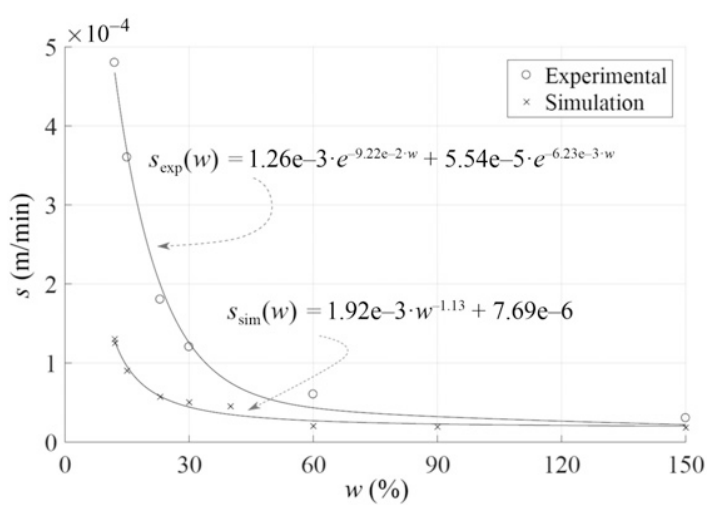

Figure 6. Moisture-dependent surface emission coefficient $s$ obtained experimentally and with the simulation model for the MC profiles illustrated in Fig 5.

values. This is especially the case at the beginning of the drying process, when the samples are above FSP.

The DC data presented by Siau and Avramidis (1996) and the data found with the fitting is presented in Fig 7. The values found with the fitting are much higher than the values found in literature. This mainly indicates that the process above FSP is much quicker. Under the section Drying above FSP, it was seen that the drying process can be divided into three phases. These phases are clearly seen in the diffusion data. The point of irreducible saturation, which divides the constant drying rate period and the pseudo-constant drying rate period, is clearly seen around $105 \% \mathrm{MC}$.

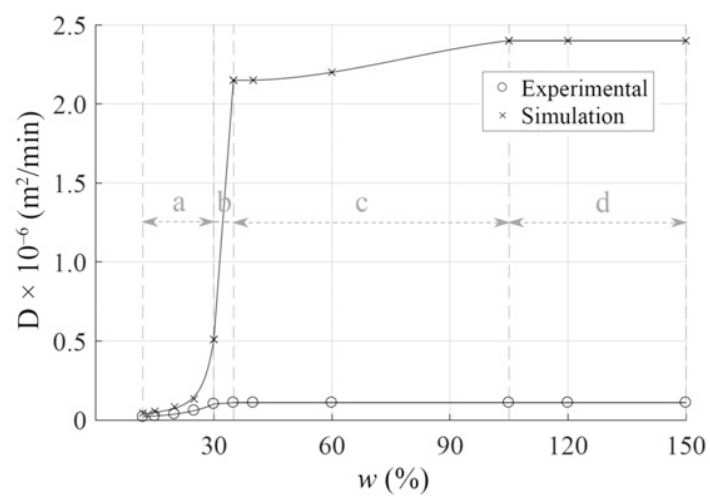

Figure 7. Moisture-dependent diffusion coefficient $D$ obtained experimentally and with the simulation model for MC profiles illustrated in Fig 5.
It can also be seen that at $31 \% \mathrm{MC}$ the decreasing drying period is starting, because of the large decrease in DC.

In the section Physical Phenomenon of Moisture Transport in Wood, different suggestions are given on how the moisture profiles look above FSP according to recent literature. The aforementioned fitting showed that a correct drying speed and shape of moisture profiles can only be found with a combination of specific SEC and DC data. The SEC mainly influences the formation of moisture gradients at the exchange surface, whereas the DC largely influences the drying speed.

\section{RESULTS AND DISCUSSION}

The two different simulations of boards introduced under the subchapter Problem Description will be indicated as $B_{n, c}$ and $B_{n, v}$, where index $c$ refers to the simulation with a constant initial MC, $v$ refers to the simulation with variation in initial MC, and $n$ is the number

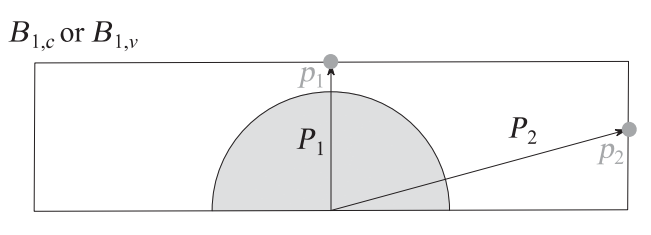

$B_{2, c}$ or $B_{2, v}$
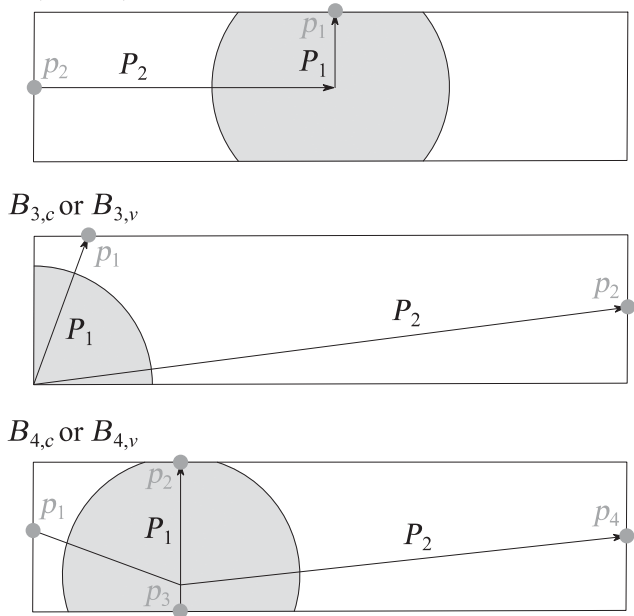

Figure 8. Orientation of paths $\mathrm{P}_{1}$ and $\mathrm{P}_{2}$ and location of material points $p_{i, c}$ and $p_{i, v}$ for the different types of timber boards that were illustrated in Fig 3. 
corresponding to the board type as illustrated in Figs 3 and 8 . The results will, among other things, be presented along two paths, which are indicated by $P_{1}$ and $P_{2}$. The results presented in material points will be indicated by $p_{i, c}$ and $p_{i, v}$, where $i$ is the number of the material point. Figure 8 shows the orientation of paths and location of material points for the different timber boards.

\section{Moisture and Stress Development in Timber Board $\mathrm{B}_{1}$}

In this section, a general discussion of the first timber board $B_{1}$ will be given based on the results found for the simulation that takes into account an initial variation in MC $B_{1, v}$. This is done to clarify most phenomena that can be expected when drying timber boards from GS to EMC and to enable an easier discussion in the next sections.

Timber boards that are subjected to drying conditions will experience a continuous change in the tangential stress state $\sigma_{t}$. In this situation, the change in state is mainly influenced by the hygroscopic and mechano-sorptive behavior of wood and can be described as stress-overturn or stress reversal. Figures 9(b) and (d) and 10(b) and (d) show this phenomenon along paths $P_{1}$ and $P_{2}$, respectively, whereas Figs 9(a) and (c) and 10(a) and (c) show the corresponding moisture profiles. It should be noted that the jump in the stress field is caused by the abrupt change in shrinking properties between heartwood and sapwood.

Norway spruce experiences a strong variation in MC between the heartwood and sapwood region in GS as was discussed in section GS MC. The moisture profile in Figs 9(a) and 10(a) at the beginning of the drying process shows an initial MC between $30 \%$ and $40 \%$ for the heartwood region ( $d$ between 0 and $40 \mathrm{~mm}$ ) and between $40 \%$ and $105 \%$ for the sapwood region. This means that the heartwood area lies closer to the FSP of 27\%. The color plots in Figs 9(c) and 10 (c) clearly show that the initial variation in MC results in a nonuniform moisture gradient along the exchange surface, which develops more rapidly below FSP in the heartwood region because of the low initial MC in this area.

The highest tensile stress values are found in the areas where the annual rings run parallel to the board's exchange surface. At the beginning of the drying process, these areas develop into a tension front, which slowly moves into the timber board, leaving behind an area in compression. This process occurs within the first 2.5 da of the drying process for path $P_{1}$ and can be seen in Fig 9(b) and (d). A similar situation is seen for path $P_{2}$ in Fig 10(b) and (c), but for a shorter period of time.

The concept of stress reversal together with the movement of the tension area creates a risk for cracks to initiate at the exchange surface and with a possible propagation into the timber board. It is seen that this process along path $P_{1}$ and $P_{2}$ takes place at different times. The maximum tensile stress for path $P_{2}$ takes longer to develop and remains greater than the critical value of $0.5 \mathrm{MPa}$ for a shorter period of time. In next section, it can be seen that this difference in process is caused by the initial moisture variation.

The area around the intersection between the sapwood and heartwood region also develops into a tension area during the drying process. This development is clearly seen in Figs 9(d) and 10(d). The tension area that develops in this region is partly caused by the difference in shrinkage properties between heartwood and sapwood, and does not show any sign of stress reversal. It is important to notice that this tension front occurs at the end of the drying process and creates a third situation where high enough tensile stress values in the tangential direction can initiate cracks. This time, the high level of tensile stress occurs within the cross-section.

\section{Maximum Tensile Stress for Boards $B_{1}$ to $B_{4}$}

Figure 11 shows the tangential stress profiles for the points in time at which the maximum stress values are found for all the simulations $B_{n, c}$ and $B_{n, v}$. The illustrations are used to analyze the influence of constant and varying initial MC on time and maximum stress size. The graphs show 


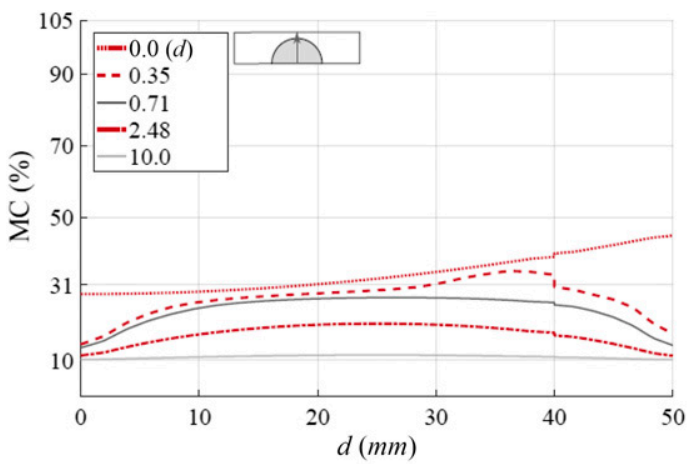

(a)

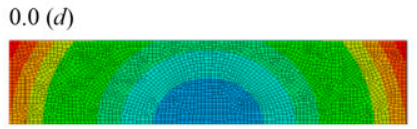

$0.35(d)$

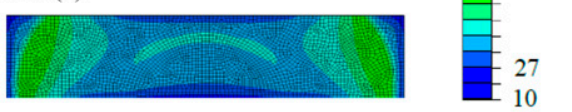

$2.48(d)$

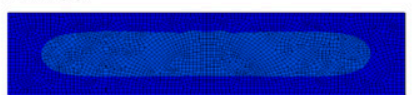

$10.0(d)$

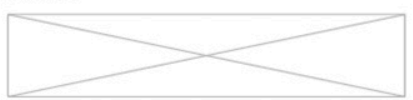

(c)

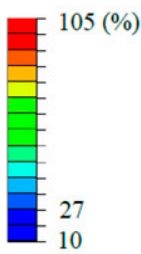

Figure 9. Illustration of $\mathrm{MC}$ and stress variation for board $B_{1, v}$ : (a) $\mathrm{MC}$ profiles along path $\mathrm{P}_{1}$ for significant times, (b) tangential stress profiles along path $\mathrm{P}_{1}$, (c) complementary $\mathrm{MC}$ color plots for some of the times used in (a), and (d) complementary tangential stress color plots for some of the times in (b). (The distortion of the cross-section is magnified 3 times.)

the tangential stress variation for the four boards presented in Figs 3 and 8 along paths $P_{1}$ and $P_{2}$.

The variation in initial $\mathrm{MC}$ influences the formation of MC-gradients early on in the drying process. The simulations with a constant initial MC showed an MC gradient that is uniform along the entire exchange surface because of the identical diffusion properties in the radial and tangential direction. The simulations with an initial variation in $\mathrm{MC}$ showed a nonuniform MC gradient, which in the beginning of the drying process quickly developed in the heartwood region in contrast to the sapwood region because of the low MC. This phenomenon results in an area within the timber boards that will start to shrink early on in the drying process and will influence (d)

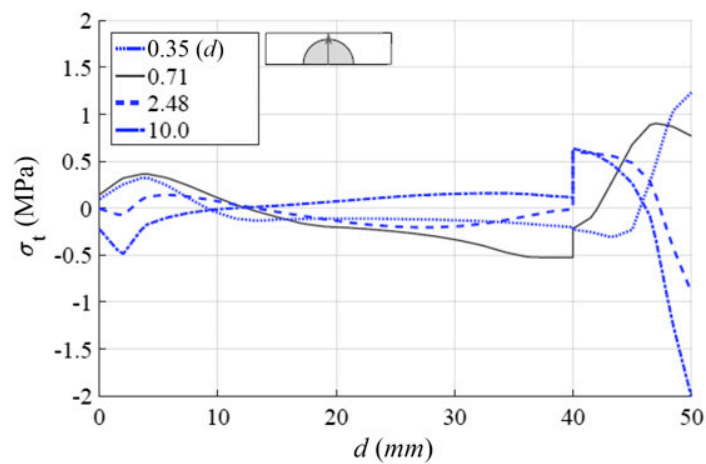

(b)

$2.48(d)$

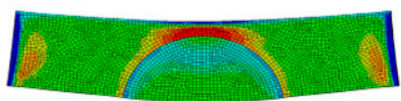

$10.0(d)$

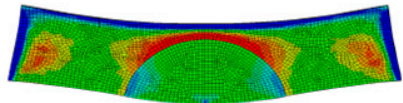

d)

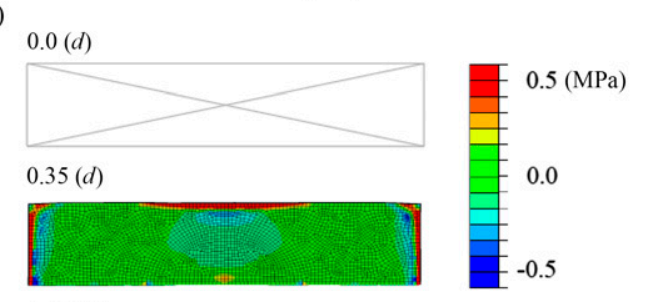




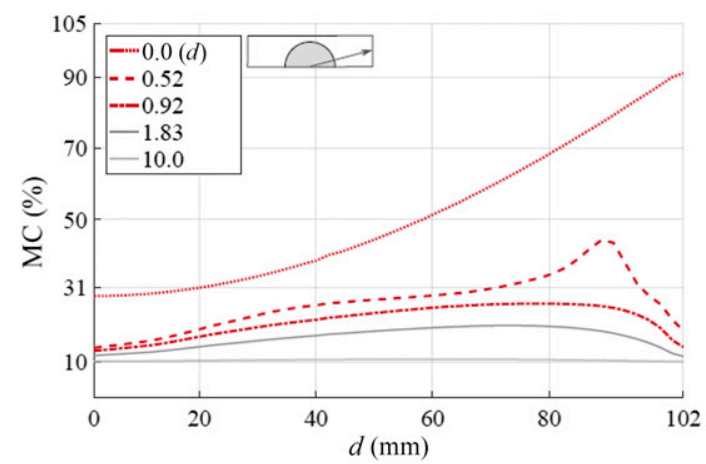

(a)

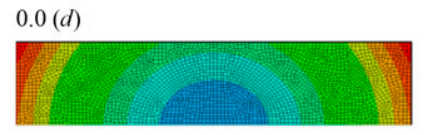

$0.52(d)$

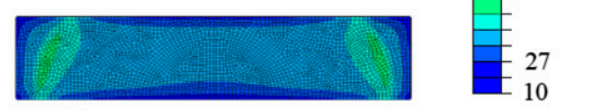

$0.92(d)$

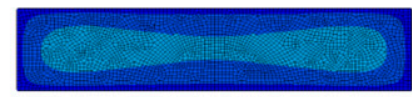

$10.0(d)$

(c)
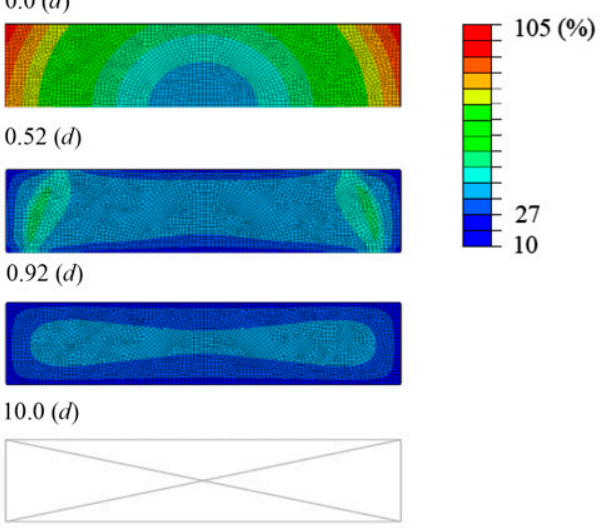

Figure 10. Illustration of $\mathrm{MC}$ and stress variation in board $B_{1, v}$ : (a) $\mathrm{MC}$ profiles along path $\mathrm{P}_{2}$ for significant times, (b) tangential stress profiles along path $\mathrm{P}_{2}$, (c) complementary MC color plots for some of the times used in (a), and (d) complementary tangential stress color plots for some of the times in (b). (The distortion of the cross-section is magnified 3 times.)

stress level because of the nonuniform MC gradient in the beginning of the drying process, which leads to a nonuniform shrinking pattern. Nevertheless, the stress level is still high enough to cause initiation of cracks.

The first row of graphs in Fig 11 corresponds to path $P_{1}$. This path runs from the lower surface to the upper surface through the pith. The second row of graphs in Fig 11 corresponds to path $P_{2}$, which runs from the left surface to the right surface through the pith. The difference in stress values between the simulations $B_{n, c}$ and $B_{n, v}$ can be found in the caption of Fig 11 in percentages. The highest stress values and the highest difference in stress values between simulations $B_{n, c}$ and $B_{n, v}$ are mostly found for path $P_{2}$. This path is most

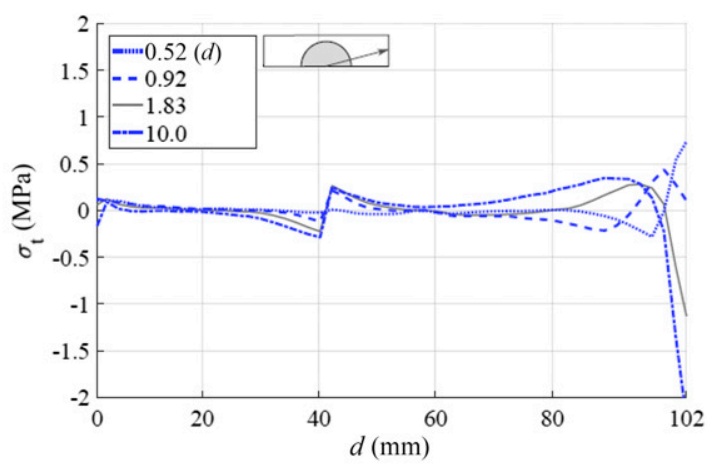

(b)
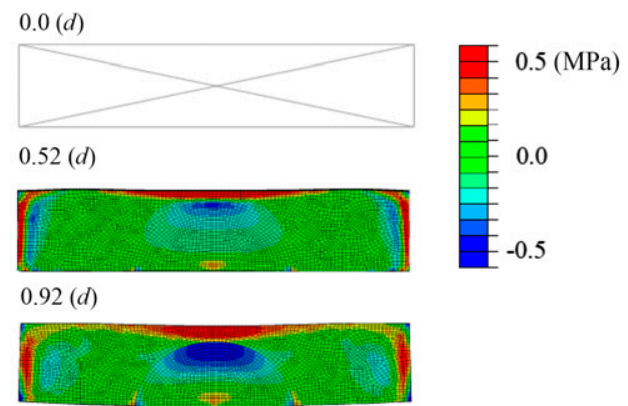

$10.0(d)$

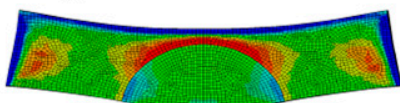

(d)

affected by the high variation in moisture. One exception is found for the symmetrical board $\mathrm{B}_{3}$. This board experiences very little cupping deformation at the end of drying, which suggests that the initial variation in $\mathrm{MC}$ and the annual ring orientation strongly influence the development of the maximum tangential tensile stress.

The time at which the highest tensile stress levels occur differ significantly between the simulations that take into account a constant initial $\mathrm{MC}$ and a variation in initial MC. In addition, the comparison made between the paths $P_{1}$ and $P_{2}$ shows that the highest stress levels for the simulations $B_{n, c}$ occur almost simultaneously in the drying process. This is not seen for the simulations $B_{n, v}$, where 


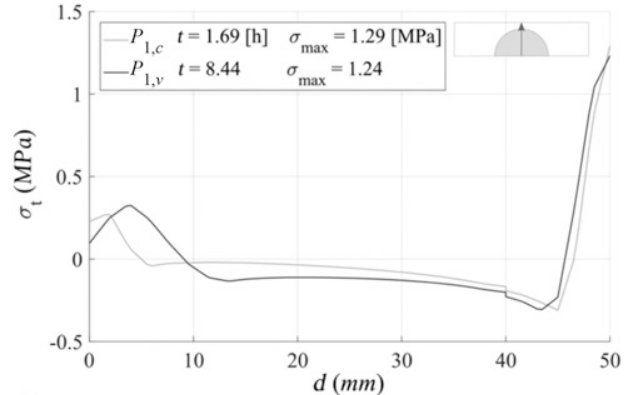

(a)

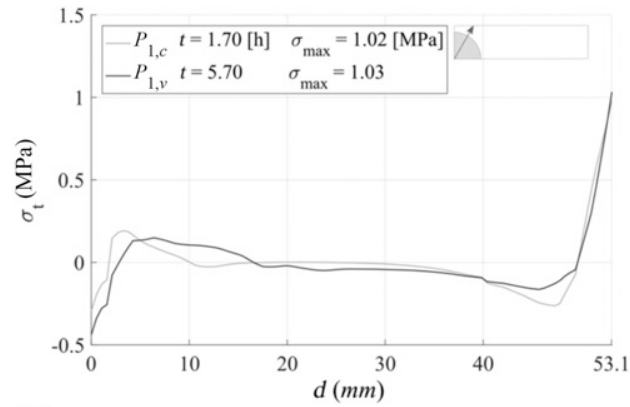

(c)

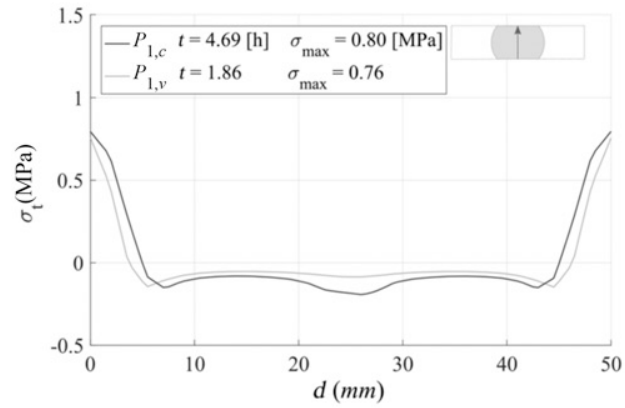

(e)

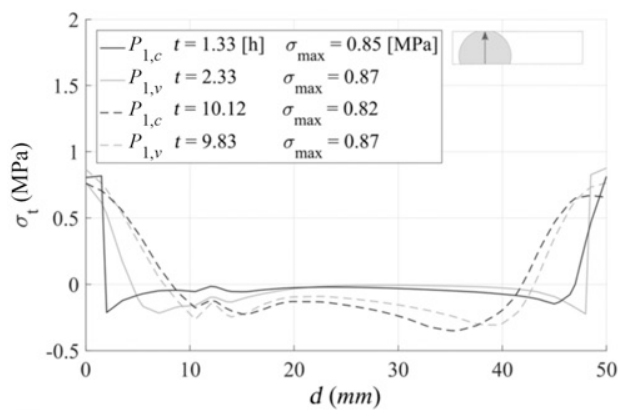

(g)

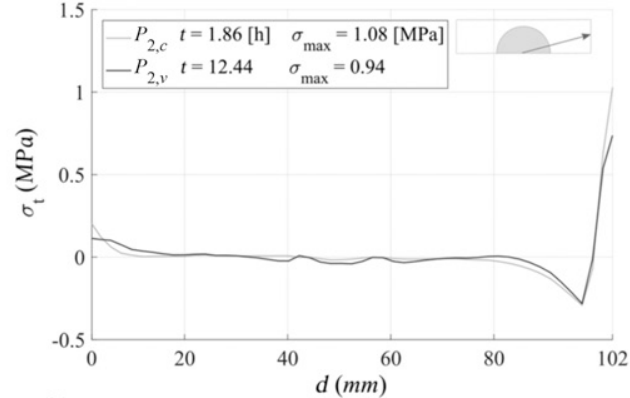

(b)

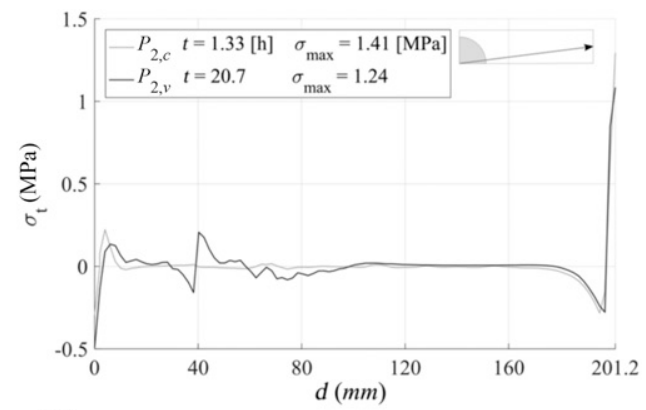

(d)

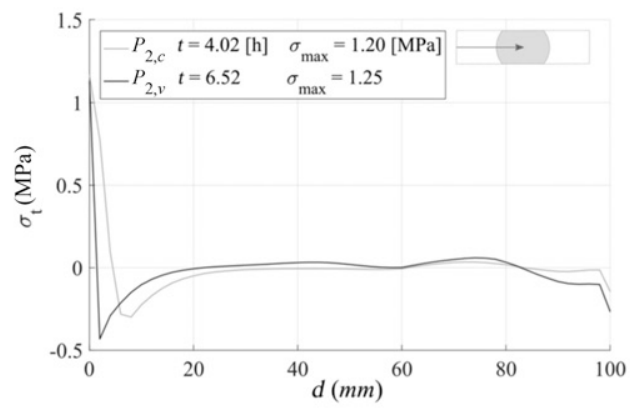

(f)

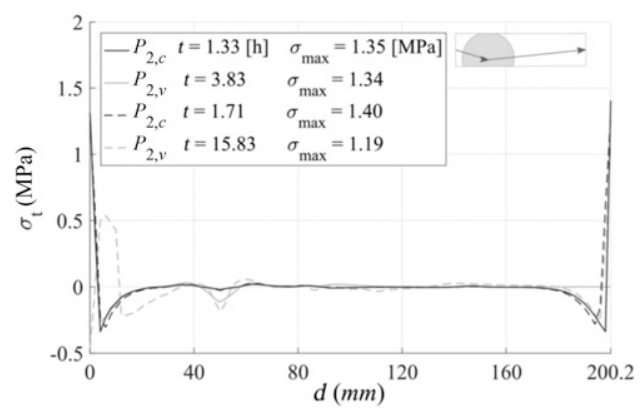

(h)

Figure 11. Path plots for tangential tensile stress states for boards $B_{n, c}$ and $B_{n, v}$ at times when maximum stress values occur. The difference in percentage between $B_{n, c}$ and $B_{n, v}$ are for (a) $P_{1}:-3.9 \%$, (b) $P_{2}:-13.0 \%$, (c) $P_{1}:+1.0 \%$, (d) $P_{2}:-12.1 \%$, (e) $P_{1}:-5.0 \%$, (f) $P_{2}:+4.2 \%$, (g) $P_{1}:+2.34 \%$ and $+6.1 \%$, and (h) $P_{2}:-0.7 \%$ and $-15 \%$. 
the variation in MC at GS seems to increase the time interval at which high stress levels between different exchange surfaces occur. This means that the initial variation in MC leads to a drying process where multiple points in time exist when cracks can develop at the exchange surface.

It is also noted that the highest tensile stress does not necessarily occur once the boards start to cup. For boards $B_{n, c}$, this would be the case, but for $B_{n, v}$, it was not. The cupping of the cross-section occurs once most of the exchange surface is sufficiently below FSP, which often does not align with the time period at which the maximum tensile stress values are formed. As a last note, it should be said that no significant trend could be found on whether the absolute difference in the GS moisture variation had an impact on the size of the tangential tensile stress.

\section{Stress Development over Time for Boards $\mathbf{B}_{1}$ to $\mathrm{B}_{\mathbf{4}}$}

Figure 12 shows the development of the maximum tangential tensile stress in time. This can be done because the area in which the maximum stress occurs is not affected by the way in which the initial MC variation is defined. Each graph in Fig 12 corresponds to a specific timber board. For each board, the material points that have been proven relevant based on the results presented in Fig 11 were analyzed.

The graphs presented in Fig 12 give more insight into the concept of stress reversal. This phenomenon is present for all simulations $B_{n, c}$ and $B_{n, v}$, and at every exchange surface, unless the pith is located directly at the surface. The graphs clearly show that the most critical stress areas first develop into a tension front, whereafter they gradually turn into a compression front. It also confirms what has been suggested in the previous section. There, it was seen that this happens in multiple points at the exchange surface and at different points in time. It is also seen that the boards with an initial variation in MC experience a stress reversal that generally takes a

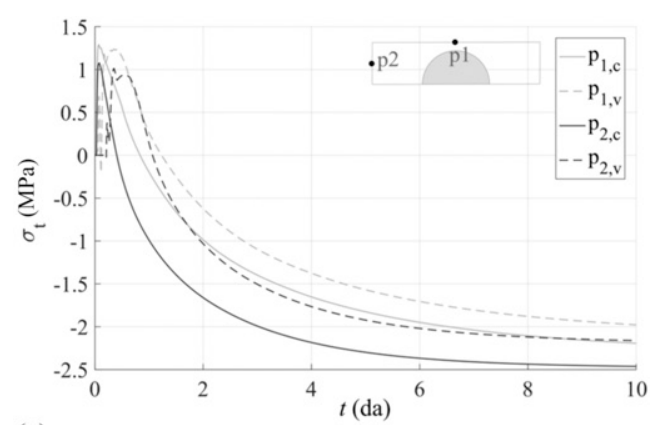

(a)

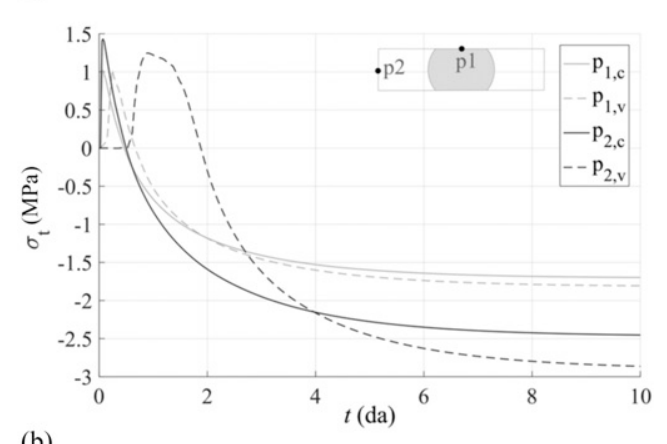

(b)

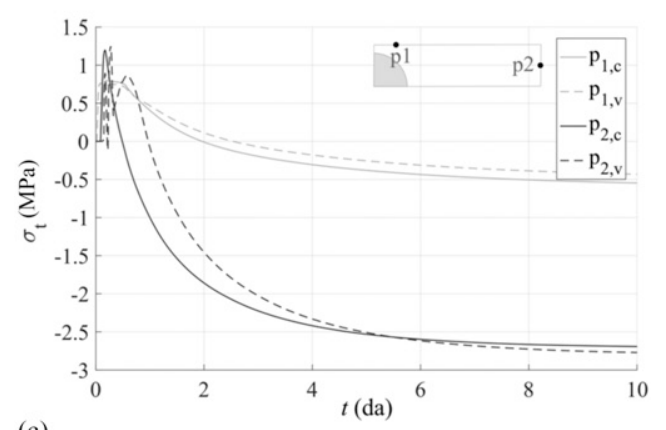

(c)

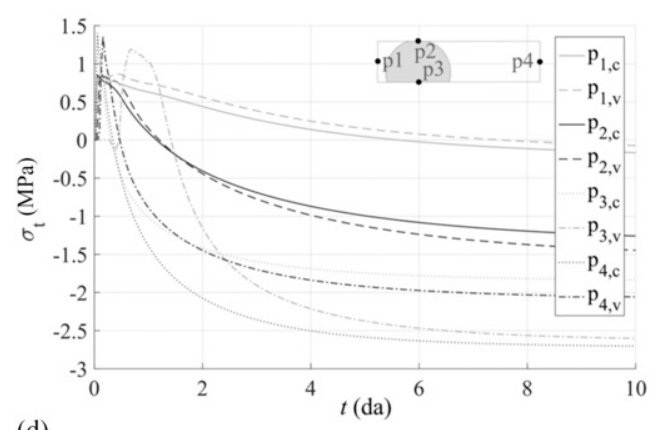

(d)

Figure 12. History plots for material points with maximum tangential tensile stress in (a) board $\mathrm{B}_{1}$, (b) board $\mathrm{B}_{2}$, (c) board $\mathrm{B}_{3}$, and (d) board $\mathrm{B}_{4}$. The maximum stress values can be found in Fig 11. 
longer period of time. This means that the peaks in tangential tensile stress continue and create a situation where it is vulnerable to crack development.

\section{CONCLUSIONS}

The development of moisture-induced tangential tensile stress has been studied by means of numerical simulations for four different configurations of Norway spruce timber boards, which were dried from GS to EMC below FSP. The results were compared with numerical results of the same boards, but with constant initial MC. The following conclusions can be drawn from the presented results and discussion:

1. The change of the moisture profiles in time over the cross-section of the studied boards is very important for the accurate prediction of moisture-induced stress development and distortion of the cross-section. The shape of these profiles and the speed in which they change is very much dependent on the correct correlation between diffusion and SEC.

2. The initial variation in $\mathrm{MC}$ at GS results in a nonuniform moisture gradient close to the exchange surface, which influences the shrinking and distortion behavior of the cross-section in the early stages of drying.

3. The variation in initial MC does not influence the location where the maximum tangential tensile stress occurs. It is seen that the areas where the annual rings align parallel to the exchange surface are prone to high levels of tensile stress and stress reversal in the early stages of drying. The areas where the heartwood and sapwood regions intersect also seem prone to high tangential tensile stress. However, the highest tensile stress in these areas often only occur at the end of the drying process and do not show any signs of stress reversal.

4. The size of the highest level of tensile stress in the tangential direction for boards $B_{n, v}$ was generally lower than that of the boards $B_{n, c}$. For boards $B_{n, v}$, the tensile stress often took a longer time to develop, was present over a longer period of time, and was high enough to cause cracking.
5. It is very important to carefully simulate the variation in MC when an accurate prediction is desired for the periods at which the highest tensile stress occurs at different exchange surfaces. At three different periods of time, high tensile stress values can be expected; two at the exchange surface where the stress reversal occurs early during the drying, and one at the interface between heartwood and sapwood at the end of the drying process.

6. All four timber boards simulated in the current study show the phenomenon of stress reversal at multiple exchange surfaces early on in the drying process. This phenomenon creates a situation where a crack can initiate and subsequently propagate, but also close later on in the drying process.

7. The previous conclusions give a picture on how critical stress situation in the tangential direction develop during the drying of timber boards. The results show that it is not only important to take into account the initial variation in $\mathrm{MC}$ to obtain a better prediction of the critical stress level, but also to get an idea of when, where, and for how long such critical situations can be experienced. The study contributes to the understanding of crack initiation and possible propagation in timber boards during drying. The picture can also greatly benefit the optimization of drying schedules designed by kiln operators.

\section{REFERENCES}

Absetz I (1999) The moisture equilibrium of softwoods above the fibre saturation point at the heartwood-sapwood boundary. Helsinki University of Technology, Espoo, Finland, TKK-TRT-101.

Bramhall G (1971) The validity of Darcy's law in the axial penetration of wood. Wood Sci Technol 5: 121-134.

Darcy H (1856) Les fontaines publiques de la ville de Dijon, exposition et application des principes a suivre et des formules a employer dans les questions de distribution d'eau. Dalmont V Editeur, Paris, France.

Dinwoodie JM (2000) Timber: Its nature and behaviour, 2nd Edition. E\&FN Spon Taylor \& Francis Group, London, UK. ISBN 0-419-25550-8. 
Eitelberger J, Hofstetter K (2011) A comprehensive model for transient moisture transport in wood below the fiber saturation point: Physical background, implementation and experimental validation. Int $\mathrm{J}$ Therm Sci 50: 1861-1866.

Eitelberger J, Hofstetter K, Dvinskikh SV (2011) A multiscale approach for simulation of transient moisture transport processes in wood below the fiber saturation point. Compos Sci Technol 71:1727-1738.

Eriksson J (2005) Moisture transport and moisture induced distortion in timber-An experimental and numerical study. PhD thesis, Department of Structural Engineering, Chalmers University of Technology, Gothenburg, Sweden.

Eriksson J, Johansson H, Danvind J (2007) A mass transport model for drying wood under isothermal conditions. Dry Technol 25:433-439.

Fick A (1995) On liquid diffusion. J Membr Sci 100: 33-38.

Fortino S, Genoese A, Genoese A, Nunes L (2013) Numerical modelling of the hygro-thermal response of timber bridges during their service life: A monitoring case-study. Constr Build Mater 47:1225-1234.

Krabbenhøft K (2003) Moisture transport in wood a study of physical and mathematical models and their numerical implementation. PhD thesis, Department of Civil Engineering, Technical University of Denmark, Copenhagen, Denmark.

Larsen F (2013) Thermal/moisture-related stresses and fracture behaviour in solid wood members during forced drying: Modelling and experimental study. $\mathrm{PhD}$ thesis, Department of Civil Engineering, Technical University of Denmark, Copenhagen, Denmark.

Larsen F, Ormarsson S (2012a) Numerical and experimental study of moisture-induced stress and strain field developments in timber logs. Wood Sci Technol 47: 837-852.

Larsen F, Ormarsson S (2012b) A numerical and experimental study of temperature and moisture related fracture behaviour in timber logs. Holzforschung.

Nijdam JJ, Langrish TAG, Keey RB (2000) A hightemperature drying model for softwood timber. Chem Eng Sci 55:3585-3598.

Ormarsson S (1999) Numerical analysis of moisture related distortion in sawn timber. PhD thesis, Department of Structural Mechanics, Chalmers University of Technology, Gothenburg, Sweden.

Ormarsson S, Dahlblom O, Petersson H (1998) A numerical study of the shape stability of sawn timber subjected to moisture variation part 1: Theory. Wood Sci Technol 32: 325-334.

Ormarsson S, Dahlblom O, Petersson H (1999a) A numerical study of the shape stability of sawn timber subjected to moisture part 2: Simulation of drying board. Wood Sci Technol 33:407-423.

Ormarsson S, Dahlblom O, Petersson H (1999b) A numerical study of the shape stability of sawn timber subjected to moisture variation part 3: Influence of annual ring orientation. Wood Sci Technol 34:207-219.

Ottosen N, Petersson H (1992) Introduction to the finite element method. Prentice Hall, London, UK. ISBN 0-13473877-2.

Pang S, Keey RB, Langrish TAG (1995) Modelling the temperature profiles within boards during the high-temperature drying of Pinus radiata timber: The influence of airflow reversals. Int J Heat Mass Transfer 38(2):189-205.

Perré P (2007) Fundamentals of wood drying. A.R.BO.LOR: Nancy, France, European COST.

Perré P, Turner IW (1999) A 3-D version of transPore: A comprehensive heat and mass transfer computational model for simulating the drying of porous media. Int J Heat Mass Transfer 42:4501-4521.

Rémond R, Perré P, Mougel E (2005) Using the concept of thin dry layer to explain the evolution of thickness, temperature, and moisture content during convective drying of Norway spruce boards. Drying Technol 23: 249-271.

Rosenkilde A (2002) Moisture content profiles and surface phenomena during drying of wood. $\mathrm{PhD}$ thesis, Building materials, KTH Royal Institute of Technology, Stockholm, Sweden.

Salin J-G (1992) Investigation of heartwood/sapwood and wood anisotropy influence on timber drying by a two-dimensional simulation model. 8th International Drying Symposium, August 2-5, Montreal, Quebec, Canada.

Salin J-G (2006a) Modelling of the behaviour of free water in sapwood during drying. Wood Mater Sci Eng 1(1): 4-11.

Salin J-G (2006b) Modelling of the behaviour of free water in sapwood during drying. Wood Mater Sci Eng 1(2): 45-51.

Salin J-G (2008) Drying of liquid water in wood as influenced by the capillary fiber network. Dry Technol 26: 560-567.

Salin J-G (2010) Problems and solutions in wood drying modelling: History and future. Wood Mater Sci Eng 5(2): 123-134.

Samuelsson A, Arfvidsson J (1994) Measurement and calculation of moisture content distribution during drying. 4th International IUFRO Wood Drying Conference, August 9-13, 1994, Rotorua, New Zealand.

Siau JF (1995) Wood: Influence of moisture on physical properties. Virginia Polytechnic Institute and State University, Keen, NY. ISBN 0-9622181-0-3.

Siau JF, Avramidis S (1996) The surface emission coefficient of wood. Wood Fiber Sci 28(2):178-185.

Skaar C (1988) Wood-water relations. Springer series in wood science. Springer-Verlag, Berlin, Germany. ISBN 3-540-19258-1.

Spolek GA, Plumb OA (1981) Capillary pressure in softwoods. Wood Sci Technol 15:189-199.

Wiberg P (1996) CT-scanning during drying. Moisture distribution in Pinus sylvestris. 5th International IUFRO 
Wood Drying Conference, August 13-17, 1996, Quebec, Canada.

Wiberg P (1998) CT-scanning of moisture distributions and shell formation during wood drying. Thesis, Division of Wood Physics, Luleå University of Technology, Skellefteå, Sweden. Wiberg P, Morén TJ (1999) Moisture flux determination in wood during drying above fibre saturation point using
CT-scanning and digital image processing. Holz Roh Werkst 57:137-144.

Yeo H, Smith WB (2005) Development of a convective mass transfer coefficient conversion method. Wood Fiber Sci 37(1):3-13.

Zienkiewicz OC, Taylor RL (1991) The finite element method. McGraw-Hill, London, UK. 